ORIGINAL RESEARCH

\title{
An Analysis of Media-Reported Venomous Snakebites in the United States, 2011-2013
}

\author{
Dennis K. Wasko, PhD; Stephan G. Bullard, PhD \\ From the Department of Mathematics and Science, Hillyer College, University of Hartford, West Hartford, CT.
}

\begin{abstract}
Background.-Venomous snakebite is a widespread natural hazard in the United States. A common perception exists that the majority of these snakebites are "illegitimate," resulting from deliberate interaction with snakes (such as attempting to move or kill the animal), but there is little quantitative information available regarding the conditions under which bites occur.

Methods. - To better understand the circumstances under which victims are bitten, we compiled a dataset of media-reported snakebites in the United States between 2011 and 2013. A total of 332 reported snakebites were recorded. Of these, 307 were from snakes encountered under natural circumstances and 25 were under captive-care conditions.

Results.-Most reported victims were adult males. Although some bites occurred during intentional handling of snakes and such activity may relate to bite severity, the majority of victims reported being unaware of the snake before they were bitten. Accidentally stepping on or placing the hands near an unseen snake were the activities most frequently associated with bites under natural conditions.

Conclusions.-Although bias in snakebite reporting patterns by the media is likely, across the United States "legitimate" bites from unseen snakes appear to be the norm.
\end{abstract}

Key words: snakes, snakebite, envenomation, rattlesnake, cottonmouth, mass media

\section{Introduction}

Venomous snakebite has a significant impact on human health, with an estimated $1,000,000$ to $5,000,000$ bites and 90,000 to 125,000 deaths occurring annually worldwide. ${ }^{1,2}$ The majority of these bites occur in tropical and subtropical regions of Africa, Asia, and Latin America, although precise figures are difficult to obtain because of often limited hospital access, lack of treatment-seeking among victims, reduced incidence reporting, and low availability of records in developing regions. ${ }^{3,4}$ Venomous snakebite incidence and mortality are much less common in the United States, but an estimated 8000 bites and 5 to 6 deaths occur annually. ${ }^{5}$

Although snakebite disease and treatment in the United States have been well reported, ${ }^{6-8}$ the circumstances under which victims encounter and are bitten by venomous snakes remains poorly documented. Furthermore, no comprehensive database of snake envenomations exists. Thus nationwide studies of venomous snakebites tend to describe patient demographics and

Corresponding author: Dennis K. Wasko, PhD, Hillyer College, University of Hartford, 200 Bloomfield Avenue, West Hartford, CT 06002 (e-mail: wasko@hartford.edu). clinical presentation, but rely on data (such as that reported to poison control centers or from voluntary hospital surveys) that contain little information about the type of snake species involved or what activity the patient was doing when they were bitten. ${ }^{9-11}$ More detailed studies, of necessity, tend to focus on datasets delineated by geographic area, ${ }^{12-14}$ patient demographics (such as children ${ }^{15,16}$ ), or individual snake species. ${ }^{17,18}$

To better understand the circumstances under which victims are bitten, we reviewed venomous snakebites across the United States from 2011 to 2013. Data were compiled from daily searches of incidents reported to national and local news agencies and to popular media. This data collection method captures only a subset of all cases and likely represents a skewed sample owing to various biases in reporting patterns. However, within this subset of cases, popular media reports also tend to include substantial detail of the actual bite event, which are often absent from more extensive snakebite reviews. Thus, assessing media-reported snakebite incidents represents a novel approach - one with both advantages and limitations-for investigating the circumstances under which human snakebites occur in the United States. Here we report on the demographics of reported bite victims 
(such as age and sex) and particularly on the circumstances surrounding and contributing to these bites.

\section{Methods}

Daily searches were conducted for snakebite-related search terms on Google News. Days were occasionally missed, but generally 28 to 30 days per month were assessed. The terms snake bite, bitten by snake, rattlesnake bite, and copperhead bite were searched during each session. Additional terms such as coral snake bite and cottonmouth bite were occasionally searched (3 to 4 times per month). Initially, these later terms were also searched daily, but experience quickly indicated that they rarely produced results and that in almost every case, articles obtained by these search terms had already been identified by more general searches (eg, bitten by snake).

Data collection began in December 2011, so it was not possible to check daily news updates for the 2011 survey year. Instead, retroactive searches were conducted for this period. Search terms including the name of each of the lower 48 states, the year, and the preceding terms were used. For example, separate search terms for a given state would include snake bite, Texas, 2011; bitten by snake, Texas, 2011; and rattlesnake bite, Texas, 2011.

Almost all articles (>95\%) located during the study were from national or local news outlets. The remaining articles came from medical or outdoor activity sites. Questionable reports, such as very short (3 to 4 lines) articles or articles from nonmainstream sources (ie, personal websites and blogs) were not included. Once articles were located, they were archived and assessed for relevant information. Specifically, articles were assessed for date, state, victim sex, victim age, whether the bite occurred in a natural setting or in captivity, the activity of the victim at the time of the bite, whether the victim was aware of the presence of the snake before the bite, the location of the bite on the victim's body, and whether the bite was fatal. Follow-up reports were rarely available for individual snakebites; in lieu of specific information to the contrary, we assume that bite victims survived.

Many reports did not contain actual victim age, but nearly all accounts contained sufficient information to infer a general age group (eg, toddler, teenage boy). Therefore, we also organized victims into age classes when possible. Age classes were defined as children (12 years and younger), adolescents (13 to 17 years), and adults (18 years and older).

We followed the convention of characterizing bite "legitimacy" based on the intentionality of exposure to bite risk. ${ }^{17}$ Legitimate bites were those resulting from accidental exposure such as stepping on a concealed snake or placing a hand in an unseen area. Illegitimate bites were those occurring as a result of deliberate interaction with the snake, such as knowingly attempting to kill or move a wild snake. Bite legitimacy was compared across sexes and across bite locations using Fisher's exact test, conducted in Systat 12.0 (Systat Software Inc, Chicago, IL).

When articles reported the type of snake responsible, we assumed that the given identification is correct. Victims sometimes took photographs of the snakes that bit them or brought dead snakes with them to medical facilities, allowing for definitive species identification. In other cases, victims self-identified the snake but did not have physical evidence. We considered these identifications correct, as Corbett et $\mathrm{al}^{19}$ demonstrated that laypeople can usually accurately identify native venomous snakes. We divided snakes into 5 broad groupings: rattlesnake (Crotalus or Sistrurus spp), copperhead (Agkistrodon contortrix), coral snake (Micrurus and Micruroides spp), cottonmouth (Agkistrodon piscivorus), and other (usually nonnative species maintained in captivity). No effort was made to differentiate between rattlesnake species as this information was not typically available.

We attempted to determine whether media-collected data provided a representative sample of all snakebites in the United States. Although no true nationwide database of snakebite cases exists, the most comprehensive dataset available is the annual reports of the American Association of Poison Control Center's National Poison Data System (NPDS ${ }^{20-22}$ ). We used $\chi^{2}$ tests to compare media and NPDS data in terms of victim age class and the type of snake responsible, and a 2-proportion $Z$ test to compare fatality rate.

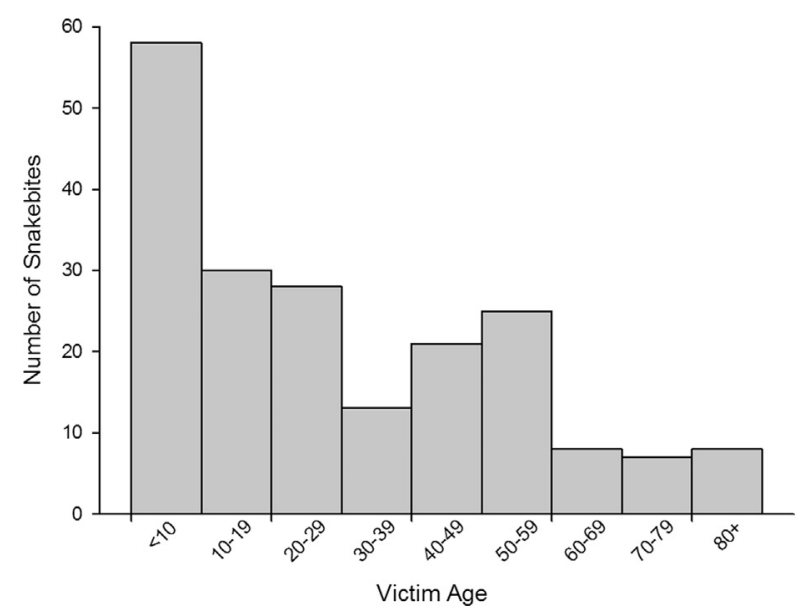

Figure 1. Age distribution of all reported snakebite victims for cases in which exact victim age was reported $(n=198)$. 


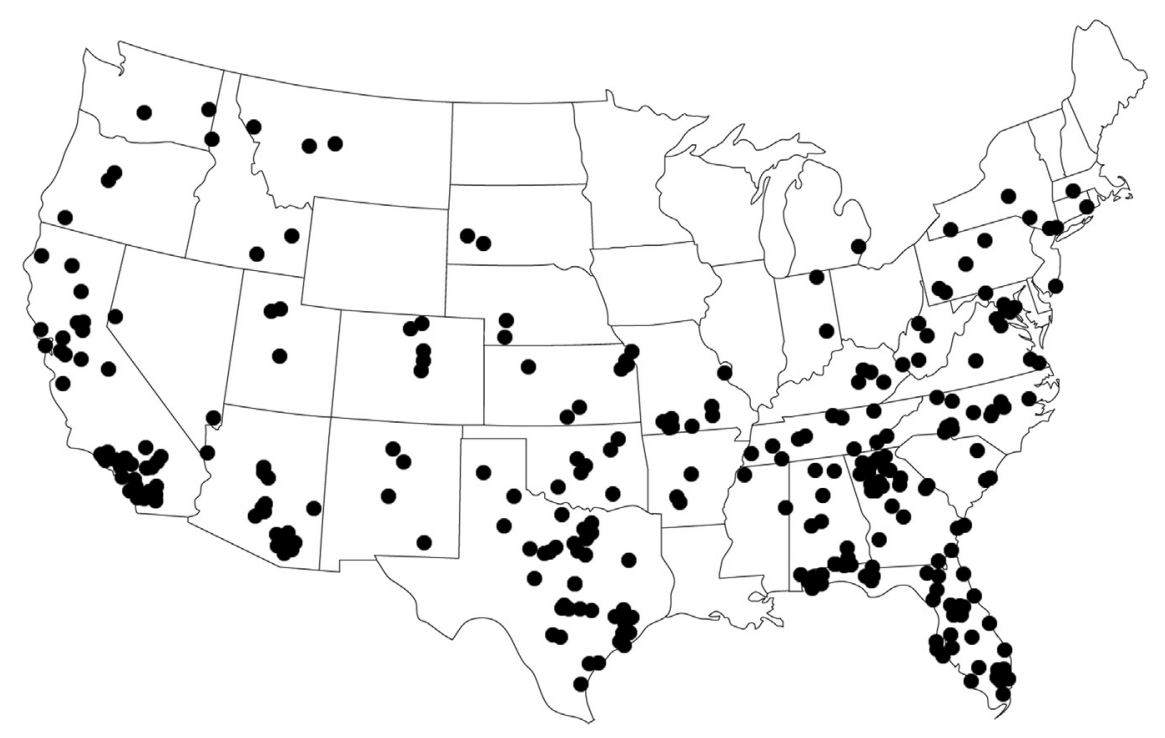

Figure 2. Approximate geographic locations of 294 snakebite cases for which location could be determined to at least the county level. Both legitimate and illegitimate bites are included, but not those occurring under captive conditions (such as from pets).

\section{Results}

\section{VICTIM DEMOGRAPHICS}

We compiled a database of 332 media-reported snakebite case reports between 2011 and 2013-129 in 2011, 111 in 2012, and 92 in 2013. All cases reported the victim's sex: $109(32.8 \%)$ bites occurred to women, $223(67.1 \%)$ to men. The victim's exact age was specified in 198 cases (Figure 1); we were able to determine victim age class for an additional 126 cases. Most victims were male $(64.3 \%)$ and adult $(76.3 \%)$, with mean victim age $( \pm 1 \mathrm{SE})$ being $28.5 \pm 1.7$ years. Bites were reported from 36 states, with the majority of cases in the southern half of the country (Figure 2).

\section{BITE CONDITIONS}

We were able to determine bite conditions (natural settings vs in captivity) for all cases. A total of 307 reported bites $(92.4 \%)$ occurred under natural conditions, $25(7.5 \%)$ were in captive-care situations. Sufficient detail to determine bite legitimacy was contained in 249 cases. Of these, 169 (67.9\%) were determined to be legitimate, those in which the victim was unaware of the snake's presence. The remaining 80 cases $(32.1 \%)$ were illegitimate bites, resulting from deliberate handling or manipulation of the snake, including all 25 of the captive-care bites. If the captive-care bites are excluded, 169 bites $(75.4 \%)$ under natural conditions were legitimate and $55(24.6 \%)$ were illegitimate.

Sex was significantly associated with bite legitimacy (Fisher's exact test, $P \leq .001$ ) when pooled across all age classes and bite conditions. Within age classes (Figure 3), sex was associated with legitimacy for children (Fisher's exact test, $P \leq .001$ ) and adults (Fisher's exact test, $P \leq .001$ ), but not for adolescents (Fisher's exact test, $P=1.0$ ). However, the sample size of cases for which both age class and bite legitimacy could be determined was much smaller for adolescents (15 bites total) than for children or adults (44 and 190 bites, respectively).

Bite location differed significantly between legitimate and illegitimate bites (Fisher's exact test, $P \leq .001$ ). For the 234 cases in which both variables were known, legitimate bites were most often $(64.8 \%)$ to the lower extremities (leg, ankle, or foot), whereas illegitimate bites were almost always $(90.1 \%)$ to the hands or fingers (Figure 4). Legitimate bite victims were most often walking or hiking at the time of the bite.

For legitimate bites under natural conditions, 169 cases reported the victim's activity at the time of the bite. Ninety-two victims $(54.4 \%)$ reported walking or hiking when bitten, and $68(40.2 \%)$ were bitten when they placed a body part in an unseen area (eg, while gardening, reaching under a shed).

Twenty-five bites $(7.5 \%)$ occurred under captive-care conditions, most often from snakes being kept as pets or zoo specimens. All of these cases were adult victims; for the 15 cases in which specific age was reported, mean age was $35.6 \pm 4.2$ years. All but 2 of these cases were male $(92 \%)$, with 1 of the female bite victims being reported as a possible suicide.

Most bites under natural conditions occurred during warmer months of the year (Figure 5). Cases that 


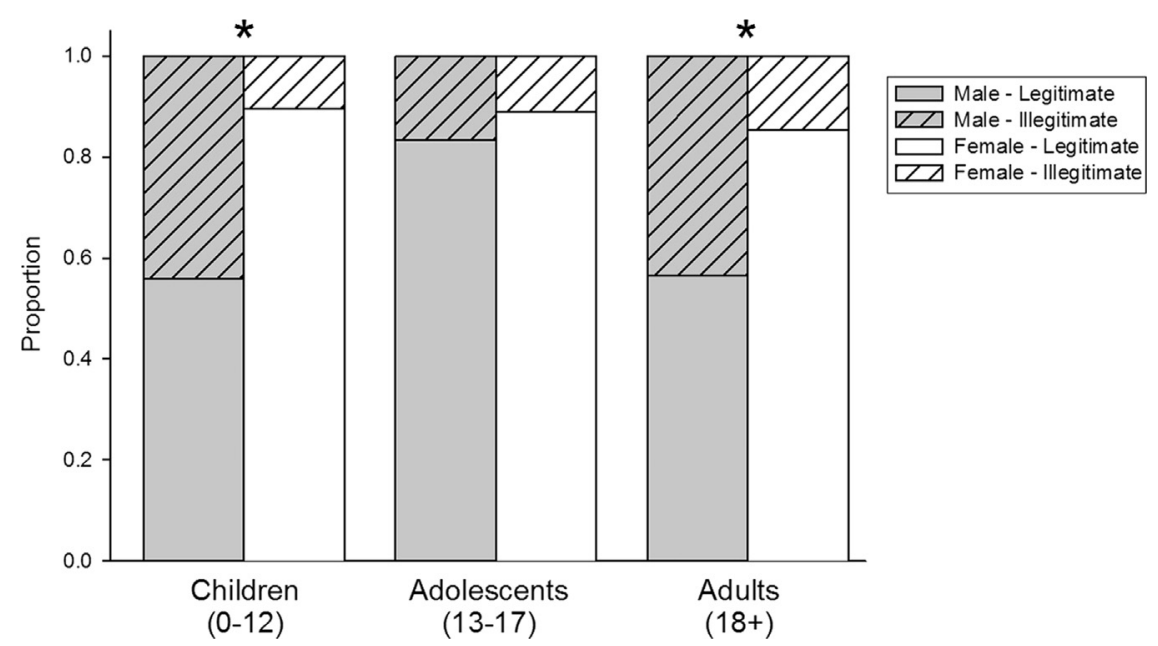

Figure 3. Proportion of legitimate (open bars) and illegitimate (striped bars) snake bites occurring to males (gray bars) and females (white bars) across 3 age classes, for cases in which all 3 factors were known $(n=249)$. Sex and bite legitimacy were significantly associated (Fisher's exact test, $P \leq .05)$ for data pooled across all age classes, and within age classes where marked with an asterisk $(*)$.

occurred during winter months (November through February) under natural conditions were almost always in southern states, most often Florida (6 of 11 bites). Bites in captivity occurred throughout the year and throughout the country.

\section{SNAKE IDENTITY}

Rattlesnakes (Crotalus and Sistrurus spp) constituted the majority of cases (170 bites, 55.4\%), with copperheads (A contortrix) accounting for 110 bites (35.8\%) (Figure 6). Bites from cottonmouths and coral snakes were much less common, accounting for $6.9 \%$ and $1.6 \%$

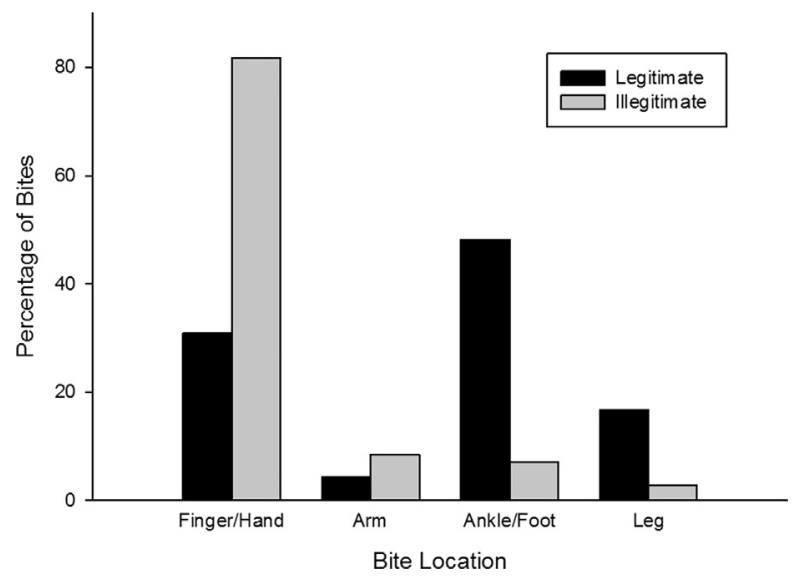

Figure 4. Legitimacy and location on the body of reported snakebite cases for which both could be determined $(n=234)$. Two outliers (1 illegitimate captive-care bite to the chest and 1 legitimate bite to the head) are excluded. Distribution of bite locations differed significantly between legitimate (black bars) and illegitimate (gray bars) bites (Fisher's exact test, $P \leq .001$ ). of all bites, respectively. The actual species of rattlesnake was very rarely reported with any certainty, and 18 species occur in the United States, so this category represents a grouping of several species, whereas the copperhead is a single species.

All bites occurring under natural conditions were from species native to the United States. Bites from nonnative species were reported only under captive conditions, and were responsible for 12 (48\%) of those bites. Nonnative species included black mamba (Dendroaspis polylepis), Chinese palm viper (Trimeresurus stejnegeri), Kanburi pit viper (Trimeresurus kanburiensis), long-nosed viper (Vipera ammodytes), puff adder (Bitis arietans), Gaboon viper (Bitis gabonica), and several cobra species (Naja kaouthia, Naja naja, and Naja haje).

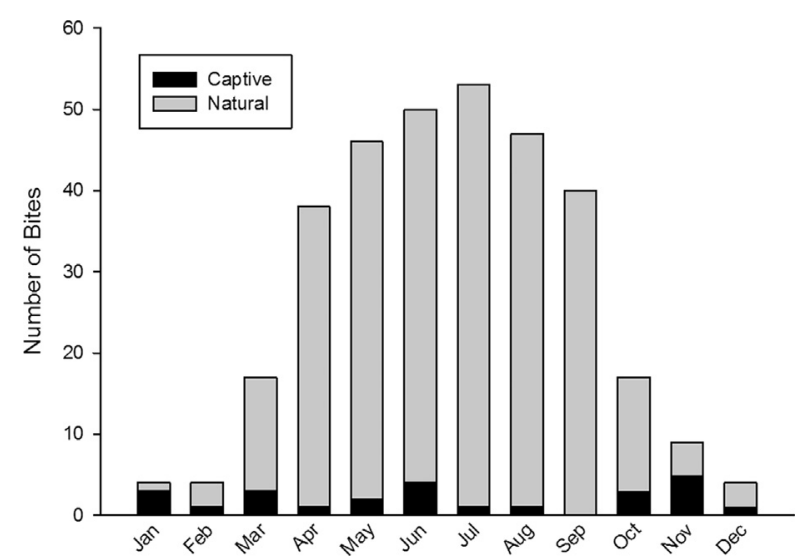

Figure 5. Monthly distribution of all snakebite cases, when included in report $(\mathrm{n}=304)$. Both captive (black bars) and natural (gray bars) bites are shown. 


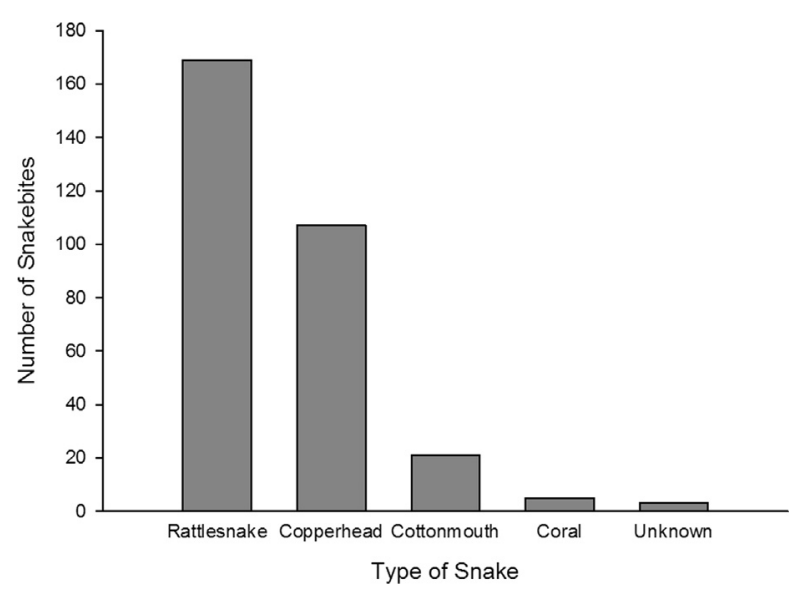

Figure 6. Type of snake responsible for bite, when included in report $(\mathrm{n}=305)$. Cases in which snake type was specifically reported as unknown are included, but not cases in which snake identity was simply unaddressed.

Ten fatalities (3.0\% of all cases) were reported. Of the 6 fatal bites occurring under natural conditions (2 copperheads, 4 rattlesnakes), 3 were clearly illegitimate, resulting from deliberately handling or trying to remove or kill the snake. Of the 3 deaths from legitimate bites, 1 was a copperhead bite to a man with a family history of severe allergic reactions; another was a rattlesnake bite to an elderly man suffering from late-stage Alzheimer's disease who was reportedly not given antivenom because of a do-not-resuscitate order. Few details were available on the third legitimate bite other than its being caused by a rattlesnake.

Four fatalities occurred from snakes maintained in captivity. Two of these were nonnative species (a black mamba and Chinese palm viper). One captive-care bite was to a preacher who was bitten while deliberately handling a timber rattlesnake (Crotalus horridus) but who did not seek medical treatment for more than 8 hours. The fourth fatality was a man bitten by a copperhead while attempting to determine its sex; the man had previously been bitten by copperheads and may have died from anaphylaxis. ${ }^{23}$

\section{REPRESENTATIVENESS OF MEDIA-REPORTED DATA}

The NPDS reports for 2011 to 2013 collectively reported 11,569 bites in the United States, compared with the 332 media-reported bites we located. These datasets differed significantly in terms of victim age distribution $\left(\chi^{2}=\right.$ 76.55, $d f=3, P<.001)$, snake species responsible $\left(\chi^{2}=124.884, d f=5, P<.001\right)$, and fatality rate $(Z=-14.040, P<.001)$. The media reported more rattlesnake bites $(54.2 \%$, NPDS $31.6 \%)$ and fewer copperhead bites (33.7\%, NPDS $42.3 \%$ ), more bites to children and adolescents 19 years and younger (44.4\%, NPDS 23.3\%), and more fatalities (3.01\%, NPDS $0.06 \%$ ). Interestingly, media reports contained more total fatalities $^{10}$ than did the NPDS. ${ }^{7}$

\section{Discussion}

Examining media-reported snakebite accounts provides a novel way to assess snakebite patterns in the United States. Existing snakebite reviews have tended to focus on snakebite pathology ${ }^{6-8,24}$ or epidemiology..$^{13,25,26}$ In contrast, the present study is more focused on the conditions and activities that led to the bite. The difference in emphasis is largely related to differences in the way the media and the clinical community collect data. Clinical reports tend to contain minimal personal detail, but a great deal of information about the pathologic effects and treatment of snakebites. Media reports vary widely, but are generally human-interest stories that extensively detail the victim's activities leading up to the bite and usually contain little information regarding medical implications of the bite.

Given these different approaches and goals, it difficult to directly compare media-reported data with clinical data. For example, the NPDS reports contained exact victim age for nearly all cases, whereas only $59.6 \%$ of media cases reported the victim's actual age. To determine the extent of these limitations, we compared the composition of media-reported data with the NPDS data. We found that the datasets differed in terms of proportions of victim ages, snake species responsible, and fatality rate. However, even though these media-reported data represent a skewed subset of all snakebite cases, they also contain substantial details not readily available elsewhere. Thus, the utility of these data lies in allowing an assessment of the types of activities contributing to bite occurrence and determination of bite legitimacy.

It is commonly claimed that most snakebites are illegitimate, occurring when a person attempts to kill, handle, or otherwise deliberately interact with a venomous snake, ${ }^{5,17,27}$ with this view occasionally supported within a particular region. ${ }^{17}$ However, in media-reported cases, the majority $(67.9 \%)$ of victims claimed to be unaware of the snake before they were bitten. When bites from captive animals are excluded, this figure increases to $75.4 \%$. Although bias in reporting patterns cannot by discounted, under natural conditions legitimate bites appear to be the norm. The majority of victims were bitten either when they were walking near an unobserved snake, or, less often, when they placed a body part into an unseen area (eg, reaching into a wood pile). As would be expected from someone accidentally 
stepping on a snake vs intentionally handling it, bite location differed significantly between legitimate and illegitimate snakebites (Figure 4). Most legitimate bites were to the lower extremities $(64.8 \%)$, whereas most illegitimate bites occurred on the hands or fingers $(81.7 \%)$.

The majority of media-reported bite victims were adults, but children younger than 10 years made up $34.8 \%$ of all reported cases, the highest for any 10-year age span (Figure 1). Even considering the media's tendency to overreport bites to children, this high prevalence may relate to a child's inability to recognize the danger presented by snakes, or to notice their presence at all. We defined age classes based on the legal recognition of adulthood at age 18, although such distinctions may be arbitrary in relation to snakebite risk. Psychological studies have correlated age with increased risk-taking behavior (which would include deliberate interaction with venomous snakes) during the period from the onset of puberty through neurological and psychological maturation in early adulthood. ${ }^{28,29}$ Accordingly, these studies defined children as those 12 years and younger, adolescents/young adults from 13 to 24 years, and adults as 25 years and older. Following such age-class guidelines might provide a more meaningful comparison of bite legitimacy with victim age. Unfortunately, only half of all adult reports provided sufficient information to determine actual victim age, making the approach unfeasible here.

There was a significant association between sex and bite legitimacy across all age classes, and within age classes for children and adults but not adolescents (Figure 3). In both cases, male victims were significantly more likely to experience illegitimate bites than female victims. This again may correspond to cognitive and psychological development, as boys are more likely than girls to underassess risk threats and to engage in risky behaviors. ${ }^{30}$ Although our sample size is relatively small, when taken in conjunction with the effects of age, the observed trends in bite legitimacy may be explained by the greater likelihood of boys than girls to willingly interact with snakes as children. This difference is reduced with both sexes' increased risktaking during adolescence, but reverts to a strong male bias with maturation to adulthood.

There was a trend for more serious envenomation to occur from illegitimate bites. A single fatality occurred in 169 legitimate bites $(0.6 \%$ fatal), whereas 8 fatalities occurred among 80 illegitimate bites (10.0\% fatal). The single legitimate fatality resulted from stepping on a copperhead, and occurred to a person who had a family history of severe allergic reactions. Eight of the 10 fatalities resulted from intentional, extended interaction with the snake-3 from actively trying to kill or move a wild snake, 5 from handling of captive snakes. The circumstances surrounding the tenth fatality cannot be definitively ascertained, but it was described as possibly a suicide through intentional snakebite. Although this is a relatively small sample size, these patterns support previous findings that snakes assess threat risks and meter their venom accordingly. Startled snakes frequently at first inflict dry bites in which little or no venom is injected, whereas direct restraint or repeated contact induces a defensive release of more venom. ${ }^{31}$ We also note that 2 of the captive-bite fatalities were from highly venomous nonnative species (black mamba and Chinese palm viper), which may have increased envenomation severity and difficulty of treatment.

Despite its convenience and prevalence in the literature, it is important to acknowledge that not all bites may fit into a simple legitimate/illegitimate dichotomy. For example, 1 case describes a bite victim who accidentally grabbed a rattlesnake thinking it was a garden hose. As the victim was in fact unaware of the snake's presence, we classified this case as a legitimate bite. However, from the snake's perspective, such accidental contact would be indistinguishable from deliberate handling. Similar reactions might be elicited from snakes that were reported as being stepped on, ridden over by a bicycle, harassed by a dog, and so forth.

Rattlesnakes (Crotalus spp) accounted for more than half of all bites (Figure 6), which is not surprising given that 18 species are distributed across much of the United States. Copperheads (A contortrix) were responsible for more than one third of reported bites; this is a single species, but one with a broad distribution across the eastern United States that can be locally abundant. ${ }^{32} A$ contortrix may therefore be the snake species responsible for the greatest number of bites. Bites from cottonmouths (A piscivorous) and coral snakes (Micrurus and Micruroides spp) were less common, accounting for $6.9 \%$ and $1.6 \%$ of media-reported bites, respectively. Both groups have limited ranges restricted to the southern parts of the country; cottonmouths can be abundant but are hesitant to bite humans, ${ }^{33}$ and the relatively small gape, short fangs, reclusive nature, and obvious coloration of coral snakes may reduce the likelihood of human envenomations under most circumstances.

All bites that occurred in natural settings were caused by native snake species. In contrast, all bites from nonnative species occurred under captive conditions, and accounted for approximately half of all captive bites. Nonnative snakes have increasingly been kept as pets or display specimens and have caused increasing numbers of envenomations in the United States. ${ }^{34,35}$ Although no introduced populations of venomous snakes 
are currently known to be established in the Unites States, bites from other nonnative snakes under natural settings may become more frequent as those populations become more common. ${ }^{36}$

Data collected for this study were obtained from popular media sources and thus should be interpreted with caution. To be included, a news agency either had to be contacted about the bite, or a reporter had to have heard about and investigated the bite. This reliance on self-reporting by victims (or at least their cooperation) may introduce biases into the dataset. For example, someone unexpectedly bitten by a snake while gardening might be more likely to contact a news agency than someone who misidentified and attempted to handle a venomous snake. Indeed, victims may wish to actively avoid media attention if they were bitten as a result of intoxication, misidentification, or illegal snake collecting or handling.

Data may be similarly skewed by reporters. For example, news agencies may be more interested in running stories about bites to young children than to middle-aged adults, explaining why media reports contained a higher proportion of bites to children than did the NPDS. More serious bites may be more likely to elicit a news story, explaining the higher proportion of rattlesnakes and lower proportion of copperheads in the media reports than in the NPDS data, as well as the higher incidence of fatalities. Novelty may be a factor, with snakebites being viewed as more newsworthy in regions where they are rare than in those where they are common. For example, we located no bite reports from Louisiana although it has several species of venomous snakes and many bites were reported from surrounding states, whereas single bites in Massachusetts and Michigan were the focus of several news stories (Figure 2). Alternatively, there may be a "repeat effect" in which a news agency becomes sensitized to snakebite and begins aggressively reporting about them. Indirect evidence for this comes from the fact that some parks or small towns reported multiple cases, whereas nearby large metropolitan regions reported few or none.

Data could also be skewed within individual reports. For example, a reporter may be willing to ask the age of young or old victims, but may not ask the age of a middle-aged victim. Additionally, where children are concerned, sufficient detail was rarely available to determine bite legitimacy, perhaps owing to the inability of very young children to explain what happened before they were bitten.

Snake species identification often relies solely on victim accounts. This is generally considered reliable, ${ }^{19}$ but in at least one case, the snake involved was reported as both a copperhead and then later as a water moccasin (cottonmouth). Similarly, additional details may emerge with time. Several cases were initially described as accidental encounters, but subsequent stories revealed that the snake had been handled deliberately. Most cases did not have follow-up stories beyond the initial report. Thus, as with other similar studies, the data collected here probably do not fully reflect the true range of all snakebites that occur in the United States. ${ }^{37}$ Note that the heavy reliance on snake-identification by the victim is constant for both media and clinical reports, so likely contributes little to the discrepancy between mediareported and NPDS data.

\section{Conclusions}

Venomous snakebite is a fairly common natural hazard, with an estimated approximately 8000 bites occurring in the United States each year. ${ }^{5}$ Even so, relatively little has been documented about the conditions under which bites occur. It appears that most bites occurring under natural conditions come from snakes that strike unexpectedly at the lower extremities of people who are unaware of the snake's presence. Bites from captive snakes occur under a very different set of circumstances-most often to the hands of people who are intentionally handling them, and potentially resulting in more serious envenomations. Future efforts should focus on determining more about the specific triggers of snakebites, especially under natural conditions. A comprehensive, nationwide database of human envenomation by snakes is also needed for future study.

\section{References}

1. Kasturiratne A, Wickremasinghe AR, de Silva N, et al. The global burden of snakebite: a literature analysis and modelling based on regional estimates of envenoming and deaths. PLoS Med. 2008;5:e218.

2. Warrell DA. Snake bite. Lancet. 2010;375:77-88.

3. Gutiérrez JM, Theakston RDG, Warrell DA. Confronting the neglected problem of snake bite envenoming: the need for a global partnership. PLoS Med. 2006;3:e150.

4. Warrell DA. Guidelines for the Management of SnakeBites. New Delhi, India: World Health Organization Regional Office for South-East Asia; 2010.

5. Gold BS, Dart RC, Barish RA. Bites of venomous snakes. N Engl J Med. 2002;347:347-356.

6. Bosak AR, Ruha AM, Graeme KA. A case of neurotoxicity following envenomation by the Sidewinder rattlesnake, Crotalus cerastes. J Med Toxicol. 2014;10: 229-231.

7. Bush SP, Jansen PW. Severe rattlesnake envenomation with anaphylaxis and rhabdomyolysis. Ann Emerg Med. $1995 ; 25: 845-848$. 
8. Scharman EJ, Noffsinger VD. Copperhead snakebites: clinical severity of local effects. Ann Emerg Med. 2001;38:55-61.

9. Langley RL. Deaths from reptile bites in the United States, 1979-2004. Clin Toxicol (Phila). 2009;47:44-47.

10. O’Neil ME, Mack KA, Gilchrist J, Wozniak EJ. Snakebite injuries treated in United States emergency departments, 2001-2004. Wilderness Environ Med. 2007;18:281-287.

11. Parrish HM. Incidence of treated snakebites in the United States. Public Health Rep. 1966;81:269-276.

12. Butner AN. Rattlesnake bites in Northern California. West J Med. 1983;139:179-183.

13. Downey DJ, Omer GE, Moneim MS. New Mexico rattlesnake bites: demographic review and guidelines for treatment. J Trauma. 1991;31:1380-1386.

14. Thorson A, Lavonas EJ, Rouse AM, Kerns WP II. Copperhead envenomations in the Carolinas. J Toxicol Clin Toxicol. 2003;41:29-35.

15. Campbell BT, Corsi JM, Boneti C, Jackson RJ, Smith SD, Kokoska ER. Pediatric snakebites: lessons learned from 114 cases. J Pediatr Surg. 2008;43:1338-1341.

16. Cruz NS, Alvarez RG. Rattlesnake bite complications in 19 children. Pediatr Emerg Care. 1994;10:30-33.

17. Curry SC, Horning D, Brady P, Requa R, Kunkel DB, Vance MV. The legitimacy of rattlesnake bites in central Arizona. Ann Emerg Med. 1989;18:658-663.

18. Morgan DL, Borys DJ, Stanford R, Kjar D, Tobleman W. Texas coral snake (Micrurus tener) bites. South Med J. 2007;100:152-156.

19. Corbett SW, Anderson B, Nelson B, Bush S, Hayes WK, Cardwell MD. Most lay people can correctly identify indigenous venomous snakes. Am J Emerg Med. 2005;23:759-762.

20. Bronstein AC, Spyker DA, Cantilena LR Jr, Rumack BH, Dart RC. 2011 Annual report of the American Association of Poison Control Centers' National Poison Data System (NPDS): 29th Annual Report. Clin Toxicol (Phila). 2012:50:911-1164.

21. Mowry JB, Spyker DA, Cantilena LR Jr, Bailey JE, Ford M. 2012 Annual Report of the American Association of Poison Control Centers' National Poison Data System (NPDS): 30th Annual Report. Clin Toxicol (Phila). 2013:51:949-1229.

22. Mowry JB, Spyker DA, Cantilena LR Jr, McMillan N, Ford M. 2013 Annual Report of the American Association of Poison Control Centers' National Poison Data System (NPDS): 31st Annual Report. Clin Toxicol (Phila). 2014;52:1032-1283.

23. Ellis EF, Smith RT. Systemic anaphylaxis after rattlesnake bite. JAMA. 1965;193:401-402.
24. Gerkin R, Sergent KC, Curry SC, Vance M, Nielsen DR, Kazan A. Life-threatening airway obstruction from rattlesnake bite to the tongue. Ann Emerg Med. 1987;16: 813-816.

25. Gold BS, Barish RA, Dart RC. North American snake envenomation: diagnosis, treatment, and management. Emerg Med Clin North Am. 2004;22:423-443. ix.

26. Walter FG, Stolz U, Shirazi F, Walter CM, McNally J. Epidemiology of the reported severity of copperhead (Agkistrodon contortrix) snakebite. South Med J. 2012; 105:313-320.

27. Minton SA. Poisonous snakes and snakebite in the US: a brief review. Northwest Sci. 1987;61:130-136.

28. Gardner M, Steinberg L. Peer influence on risk taking, risk preference, and risky decision making in adolescence and adulthood: an experimental study. Dev Psychol. 2005;41: 625-635.

29. Steinberg L. Risk taking in adolescence: new perspectives from brain and behavioral science. Curr Dir Psychol Sci. 2007; 16:55-59.

30. Hillier LM, Morrongiello BA. Age and gender differences in school-age children's appraisals of injury risk. J Pediatr Psychol. 1998;23:229-238.

31. Hayes WK, Herbert SS, Rehling GC, Gennaro JF. Factors that influence venom expenditure in viperids and other snake species during predatory and other contexts. In: Schuett GW, Höggren M, Douglas ME, Greene H, eds. Biology of the Vipers Eagle Mountain, UT: Eagle Mountain Publishing; 2002:207-233.

32. Titus V, Zimmerer E. Road effects on a population of copperhead snakes in the Land Between the Lakes National Recreation Area, KY. In: Iriwn CL, Nelson D, McDermott KP, eds. Proceedings of the 2007 International Conference on Ecology and Transportation. Raleigh, NC: Center for Transportation and the Environment, North Carolina State University; 2007;207:378-385.

33. Gibbons JW, Dorcas ME. Defensive behavior of cottonmouths (Agkistrodon piscivorus) towards humans. Copeia. 2002;2002:195-198.

34. Minton SA. Bites by non-native venomous snakes in the United States. Wilderness Environ Med. 1996;7:297-303.

35. Seifert SA, Oakes JA, Boyer LV. Toxic Exposure Surveillance System (TESS)-based characterization of U.S. non-native venomous snake exposures, 1995-2004. Clin Toxicol (Phila). 2007;45:571-578.

36. Dorcas ME, Willson JD. Invasive Pythons in the United States Athens, GA: University of Georgia Press; 2011.

37. Hayes WK, Mackessy SP. Sensationalistic journalism and tales of snakebite: are rattlesnakes rapidly evolving more toxic venom? Wilderness Environ Med. 2010;21:35-45. 